\title{
STRAIN ANALYSIS OF VAPOR CHAMBER HEAT SPREADERS
}

Yu-Hsun Hung

Department of Mechanical and Electro-Mechanical Engineering,Tamkang University,Tamsui, Taipei County, Taiwan, R.O.C.

Shung-Wen Kang

Department of Mechanical and Electro-Mechanical Engineering, Tamkang University, Tamsui, Taipei County, Taiwan, R.O.C., swkang@mail.tku.edu.tw

Wan-Chun Tsai

Department of Mechanical and Electro-Mechanical Engineering,Tamkang University,Tamsui, Taipei County, Taiwan, R.O.C.

Follow this and additional works at: https://jmstt.ntou.edu.tw/journal

Part of the Electrical and Computer Engineering Commons

\section{Recommended Citation}

Hung, Yu-Hsun; Kang, Shung-Wen; and Tsai, Wan-Chun (2010) "STRAIN ANALYSIS OF VAPOR CHAMBER HEAT SPREADERS," Journal of Marine Science and Technology. Vol. 18: Iss. 2, Article 14.

DOI: $10.51400 / 2709-6998.2327$

Available at: https://jmstt.ntou.edu.tw/journal/vol18/iss2/14

This Research Article is brought to you for free and open access by Journal of Marine Science and Technology. It has been accepted for inclusion in Journal of Marine Science and Technology by an authorized editor of Journal of Marine Science and Technology. 


\title{
STRAIN ANALYSIS OF VAPOR CHAMBER HEAT SPREADERS
}

\author{
Yu-Hsun Hung*, Shung-Wen Kang*, and Wan-Chun Tsai*
}

Key words: heat spreader, vapor chamber, strain, finite element method.

\begin{abstract}
Vapor chamber is a cooling device with phase change phenomena. It not only provides high heat transfer coefficient but also removes hot spot. During working of vapor chamber, the buckle force and vapor pressure could lead to deformation. It is a popular way that pillars are set up to reduce deformation. This paper presents a three-dimensional finite element analysis for the vapor chamber by ANSYS software program. Four pillars with two kinds of designs are built into vapor core in order to avoid deformation of the vapor chamber. The results appear that pillars inside vapor chamber are good to reduce strain up to $81-91 \%$. The effects of thickness, materials, and heater sizes on the strain are discussed. The optimum pillar design can be obtained by cooperating with heater sizes, although the effective heat area may be possibly reduced. The results attained that the appropriate design of pillars could enhance structure performance of the vapor chamber.
\end{abstract}

\section{INTRODUCTION}

Recently, the electronic components are more and more highly concentrated and are dissipated more heat. High heat dissipation and high density of components causes heat to centralize on the components that it is called hot spot. Hot spot can lead to increasing the operating temperature of electronic components. The operating temperature exceeds the allowing temperature and makes the components failure or damage. Consequently, heat removal and low operating temperature are important factors in electronic components.

The vapor chamber is a cavity of small thickness which is filled with the working fluids and is fitted between the top of the heat source and the bottom of the heat sink. When the heat is transferred from the heat source, the working fluids absorb heat and evaporate in the evaporator. The vapor moves to the condenser through a vapor core. The vapor of working fluids

Paper submitted 12/05/08; accepted 06/08/09. Author for correspondence: Shung-Wen Kang (e-mail: swkang@mail.tku.edu.tw).

*Department of Mechanical and Electro-Mechanical Engineering,Tamkang University,Tamsui, Taipei County, Taiwan, R.O.C. dissipates heat and condenses into the liquid. The liquid returns from the evaporator to the condenser through a capillary structure made of micro-grooves, meshes or sintered powder wicks. This cycle completes the heat transfer.

There are several important factors which include the cycle of working fluids, the performance of condensers, the capillary force by wick structures, and the smaller contact thermal resistance in order to keep high heat transfer coefficient of a vapor chamber. Contact thermal resistance takes place the interface between the vapor chamber and heat sources or heat sinks. The surface flatness is defined as space irregularity, and the surface roughness is the submicron scale irregularities of a surface. Lower surface flatness and higher surface roughness show that the contact interface arranges air gaps. Air gaps represent a significant resistance to heat transfer because air is a good thermal isolation. In order to reduce contact thermal resistance, thermal interface material is used to fill air gaps at present.

The surface roughness is resulted from properties of materials such as porosity, and machining, usage, or wear. They are general ways to improve the surface roughness by milling or polishing with sandpapers. The surface flatness is affected by fabricating, outside force, and inside force. The vapor chamber may be caused by clipping, cutting, or machining during fabricating. The outside force indicates that the vapor chamber assembles heater or heat sink. From Fig. 1, this situation could deform the surface of the vapor chamber. The inside force represents that vapor pressure generates in the vapor core and the heat makes expansion and the cold causes contraction during heating process. Consequently, there is an important topic to preserve surface flatness and decrease surface roughness for performance of the vapor chamber.

Presently, the literatures about analysis of thermal stresses and deformations are focus on the package design. In 1990, Chanchani and Hall [1] measured thermal expansion over the range of $-40-140^{\circ} \mathrm{C}$ of several of the ceramics used in modern hybrids, single-chip packages, and multichip modules, and compared these thermal expansion data to those of silicon and the materials used for leads, lids, heat spreaders, and sinks. Based on these measurements, the package designer can make appropriate materials choices to void the problem caused by large thermal stresses.

In 2001, Rodriguez and Shammas [10] used the commercial software ANSYS to set and compute simplified thermal and 


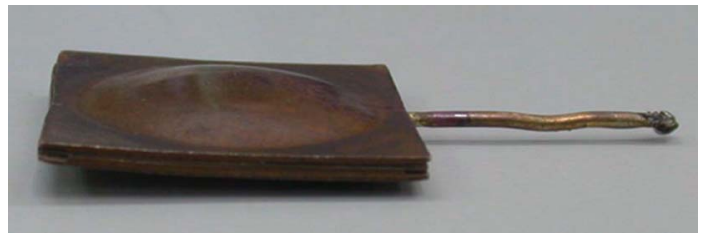

Fig. 1. Deformation of vapor chamber.

mechanical finite element models which were presented for the analysis of thermal stresses derived problems. The problems included thermal stresses in adhesive backbones in surface mounted structures and effects of thermal fatigue in soft solder interfaces in conventional power modules. Furthermore, results of the simulation compared well with contact temperature measurement data, and maximum errors are found between $3 \%$ and $10 \%$. Chiang et al. [2] presented a compact analytical thermal model to evaluate temperature distribution in three dimensional ICs including via effect by ANASYS. Temperature performance of various three dimensional integration schemes had been examined thoroughly. Huja and Husak [6] used ANSYS software to simulate the deformation of thermal microactuators. The ANSYS program is simulated the temperature distribution of microactuators and evaluated thermal stresses and deformation.

In 2003, Chong et al. [3] used finite element analysis to simulate thermal performance of the package. The packages are designed two-piece and one-piece lids. Coefficient of thermal expansion mismatch between the lid and substrate gave rise to different induced stresses in the package. Results showed that the two-piece design generated a lower package warpage, thus allowing better surface mounting.

In 2004, Zhang et al. [12] presented a thermal-mechanical analysis of a multichip module (MCM) package design. The analysis included thermal-mechanical analysis of the MCM package without, with a heat spreader, and solder joint reliability modeling. Results showed that increasing the heat spreader thickness by $50 \%$ would lead to $8 \%$ reduction respectively in the warpage and would lead to $12 \%$ reduction in solder joint fatigue life. Vadakkan et al. [11] presented the vapor chamber for microelectronic packages. The vapor chamber consisted of bottom wall, wick, vapor core, and top wall. Two-dimensional flow and energy equations were solved in the vapor and liquid regions along with conduction in the wall. In addition to thermal modeling, finite element analysis was performed to study the impact of the proposed vapor chamber design on die stresses. The study shows that a silicon/water vapor chamber can match or thermally perform better than a more standard copper spreader while also reducing the compressive stress in the silicon by as much as $96 \%$. Thus silicon vapor chambers provide good design alternative to a standard copper heat spreader without compromising on the reliability and performance of silicon.

In 2005, Kim et al. [7] investigated the high-end flip chip ball grid array (FCBGA) package. This analysis was made use of improving this problem which was induced by thermal expansion mismatch.
In 2008, Do et al. [5] presented that a mathematical model is developed for predicting the thermal performance of a flat micro heat pipe with a rectangular grooved wick structure. The effects of the liquid-vapor interfacial shear stress, the contact angle, and the amount of liquid charge are accounted for in the present model. Chuang et al. [4] focus on a flip chip package which was assembled by using six layers. These results obtained that choosing a correct underfill material was the key factor for volume production of coreless flip chip package. Lee et al. [8] compared experimental modal analysis with finite element model for a standard joint electron device engineering council drop test printed circuit board mounted with package. Natural frequencies and mode shapes obtained by EMA and FEA are generally in very good agreement. Qi [9] analyzed a thermally enhanced ball grid array package (TEBGA) deformation and these results impacted on package thermal performance. The procedure is suggested that shows a way to achieve a balanced solution.

This paper focuses on a three-dimensional finite element analysis for the vapor chamber by ANSYS software program. Four pillars are built into vapor core in order to avoid deformation of surface of the vapor chamber during the heat transfer working. The results obtain from the design of pillars are useful in increasing structure performance of the vapor chamber.

\section{DEFORMATION OF THE VAPOR CHAMBER}

Deformation of the vapor chamber is due to heating, cooling, or welding. In order to combine all components and ensure a vacuum, welding is a usually way. It approximately divides into tungsten inert-gas arc welding (TIG), metal inert-gas arc welding (MIG), and diffusion bonding. TIG and MIG present that materials joint with solders. These methods suit to combining with heterogeneous materials. Diffusion bonding is a joining process as a subdivision of both solid-state welding and liquid-phase welding. Bonds are established by the formation and solidification of a liquid phase at the interface and then the applied pressure brings together the surface to be jointed within interatomic distances. Diffusion bonding of most metals is conducted in vacuum or in an inert atmosphere (such as nitrogen, argon, or helium) in order to reduce detrimental oxidation of the faying surfaces and ensure the combination strength. These methods are identical essentials which the combinations have to heat or cool. The processes are possible to cause to deformation.

Pillars inside vapor chambers are the way to avoid deformation. This paper focuses on simulating to lay pillars on the location of the vapor chamber. The size of the vapor chamber is $54 \mathrm{~mm} \times 54 \mathrm{~mm} \times 6 \mathrm{~mm}$ shown in Fig. 2. The diameter and thickness of pillar are $4 \mathrm{~mm}$ and $4 \mathrm{~mm}$ respectively. The locations of pillars inside vapor core are defined by design.

With ANSYS software program, A three dimensional finite element is analyzed for a column design. The results suggest design of vapor chambers. 


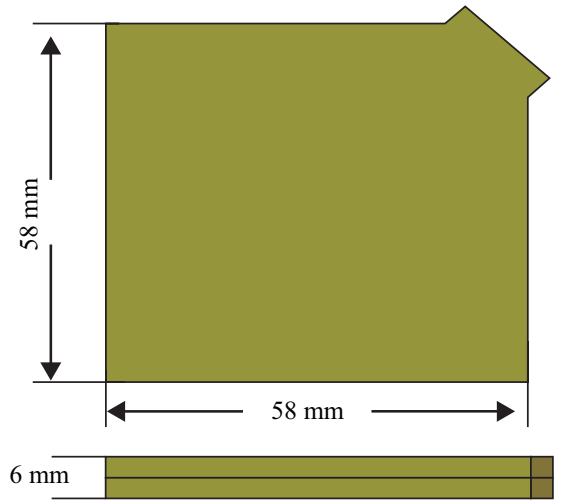

Fig. 2. Dimension of vapor chamber.

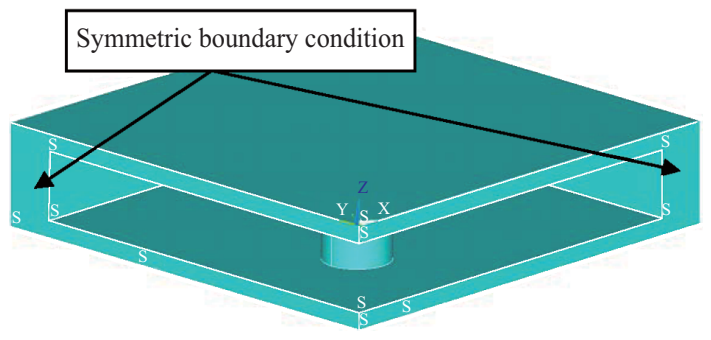

Fig. 3. Symmetrically quartered finite element model.

\section{FINITE ELEMENT MODEL}

\section{Assumptions}

A process to perform thermal analysis of vapor chambers in the section. Thermal analysis determines the residual stress and strain distribution within the vapor chamber when it is worked. Finite element model is set up a symmetrically quartered model to simplify simulation procedure shown in Fig. 3.

There are several assumptions for the simulated models listed below:

(1) Steady-state.

(2) Coefficient of thermal expansion does not vary with temperature.

(3) The material is homogeneous.

(4) The ambient temperature is $30^{\circ} \mathrm{C}$.

(5) All interfaces of components adhere perfectly to each other.

(6) Do not consider heat radiation.

(7) Lateral walls of the vapor chamber are adiabatic.

Simulation starts building the model geometry and meshing the pre-processor. The quartered model is set up the symmetric boundary condition. The finite element model uses ten-nodded three-dimensional solid elements (SOLID 98) which structure analysis couples with thermal analysis. According to the working process of vapor chamber, model loading conditions are listed below.

\section{Loading Conditions}

Table 1. The physical property.

\begin{tabular}{|c|c|}
\hline Property & Copper \\
\hline Young's modulus & $1.2 \times 10^{11} \mathrm{~N} / \mathrm{m}^{2}$ \\
\hline Poisson's ratio & 0.33 \\
\hline Density & $8933 \mathrm{~kg} / \mathrm{m}^{3}$ \\
\hline Thermal conductivity & $374 \mathrm{w} / \mathrm{m} \cdot{ }^{\circ} \mathrm{C}$ \\
\hline Coefficient of thermal expansion & $1.6 \times 10^{-6} \mathrm{~m} /{ }^{\circ} \mathrm{C}$ \\
\hline
\end{tabular}

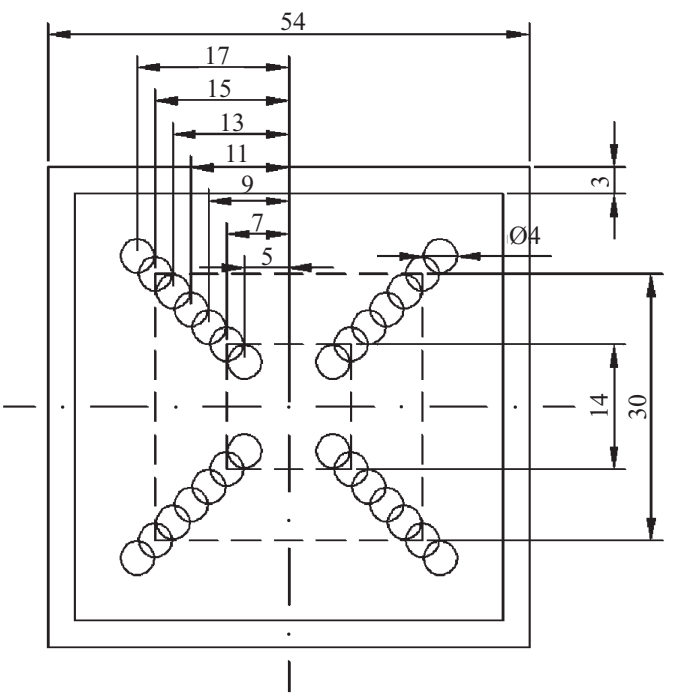

Fig. 4. Type I for heater size of $14 \times 14 \mathrm{~mm}^{2}$ and $30 \times 30 \mathrm{~mm}^{2}$.

The heat power of $100 \mathrm{~W}$ is input the bottom surface of the vapor chamber, and the heater area are $14 \times 14 \mathrm{~mm}^{2}$ and $30 \times$ $30 \mathrm{~mm}^{2}$ respectively. The convection heat transfer coefficient which represents that the heat sink condenses the vapor chamber is set to $300 \mathrm{~W} / \mathrm{m}^{2} \cdot{ }^{\circ} \mathrm{C}$ on the top surface. In order to reduce thermal contact resistance, the heat sink attaches to the vapor chamber. Hence, the buckling force is set to $12.5 \mathrm{kgf}$ on the top surface. The vapor chamber with a heat sink is attached to heat source. Therefore, constraints are set to the interface between a heater and a vapor chamber. The inside planes of vapor chamber and the outside of columns are set saturated vapor pressures which is 0.4739 bar at $80^{\circ} \mathrm{C}$. The buckling force of $12.5 \mathrm{kgf}$ and constraints are also set on top surface.

The material of vapor chamber is copper and the physical properties are shown in Table 1. Pillars are located in $5 \sqrt{2}(7.071)-17 \sqrt{2}(24.042) \mathrm{mm}$ away from the center of the vapor chamber on a quartered model. The inclined angles of pillar location are $45^{\circ}$ and $0^{\circ}$ for heater sizes of $14 \times 14 \mathrm{~mm}^{2}$ and $30 \times 30 \mathrm{~mm}^{2}$ illustrated in Fig. $4-5$ respectively and they are defined as Type I and Type II.

\section{THERMAL ANALYSIS OF VAPOR CHAMBER HEAT SPREADERS}

\section{Type I for Inclined Angle $4^{\circ}$}

The stress distribution of vapor chamber with and without a 


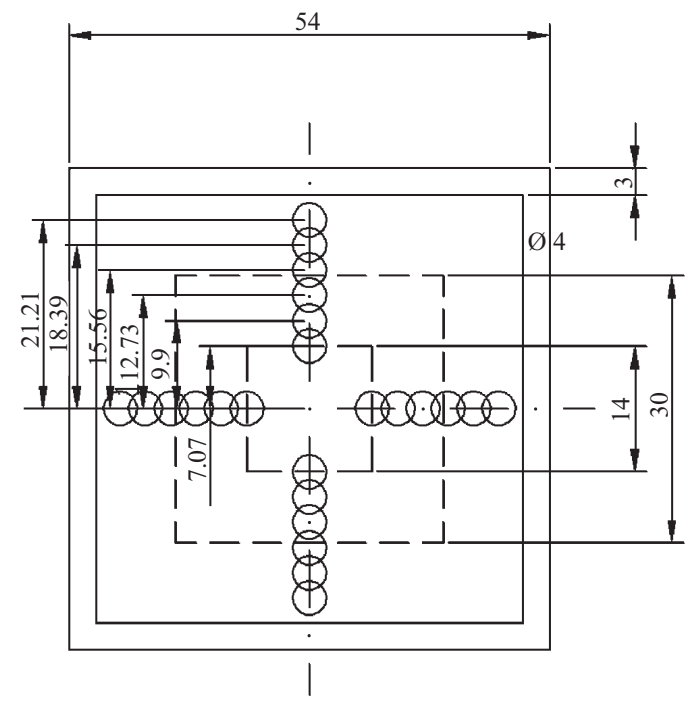

Fig. 5. Type II for heater size of $14 \times 14 \mathrm{~mm}^{2}$ and $30 \times 30 \mathrm{~mm}^{2}$.

pillar distance from the center of $7 \sqrt{2} \mathrm{~mm}$ for heater size of $14 \times 14 \mathrm{~mm}^{2}$ are shown in Figs. 6-7. For a vapor chamber with a pillar, the maximum stress for is occurred at the bottom of the pillar. The stress centralization is due to holding a vapor chamber by a pillar. The stress distribution of a vapor chamber without a pillar contours from the center and the maximum stress occurs at the interface of center between a heater and a vapor chamber. The pillar promotes to reduce stress centralization in the bottom surface of vapor chamber.

The relation of the position and strain on the bottom surface of a vapor chamber is shown in Fig. 8. Strains along the $\mathrm{x}$-directional line and diagonal will be discussed. Comparison with strains along the $\mathrm{x}$-directional line and diagonal are shown in Figs. 9(a)-(d). For heater size of $14 \times 14 \mathrm{~mm}^{2}$ and $30 \times$ $30 \mathrm{~mm}^{2}$, the pillar position $5 \sqrt{2} \mathrm{~mm}$ for inclined angle $45^{\circ}$ lead to the minimum strains at the center of bottom surface which are $1.2758 \times 10^{-4}$ and $2.2303 \times 10^{-5}$ respectively. Compare with none of pillars, the decreases in stains at the center with a pillar of position $5 \sqrt{2} \mathrm{~mm}$ for heater sizes of $14 \times 14 \mathrm{~mm}^{2}$ and $30 \times 30 \mathrm{~mm}^{2}$ are about $82 \%$ and $91 \%$. Within the section of a vapor core, the strains increase with $\mathrm{x}$-direction and decrease near the wall because it exists saturated vapor pressure.

Along the diagonal direction, it is obvious that the strain changes exist in the pillar area. Increasing strain occurs at the front of a pillar area and the strain gradually decreases along a pillar area except for ones with a pillar of $5 \sqrt{2} \mathrm{~mm}$ and none. Within the vapor core area, setting a pillar causes significant strain change. However, the strain change is slight within the other area for the vapor core. In other words, pillars sustain the vapor chamber and furthermore cause significant strain changes, especially pillars which are built away from the heater area.

\section{Type II for Inclined Angle $0^{\circ}$}

The stress distribution of vapor chamber with a pillar of position $7 \sqrt{2} \mathrm{~mm}$ for heater size of $14 \times 14 \mathrm{~mm}^{2}$ are shown in Fig. 10. The maximum stress is located at the interface be-

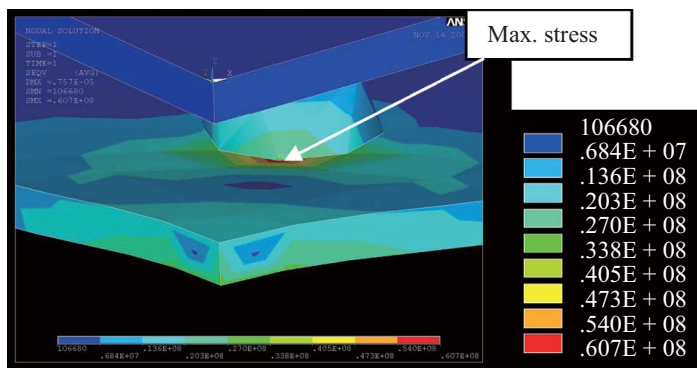

Fig. 6. The stress distribution of vapor chamber with a pillar of Type I distance from the center of $7 \sqrt{2} \mathrm{~mm}$ for heater size of $14 \times 14$ $\mathbf{m m}^{2}$.

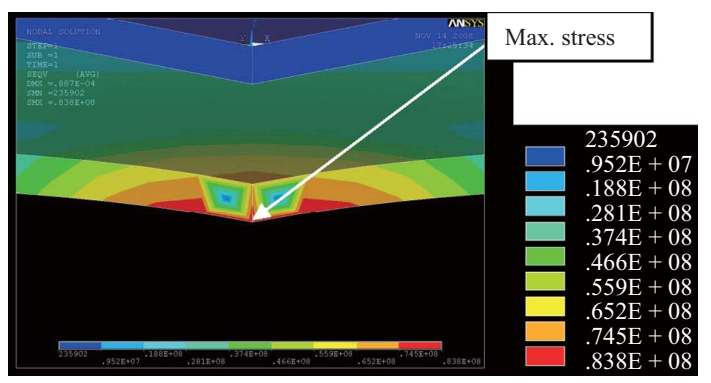

Fig. 7. The stress distribution of vapor chamber without a pillar distance from the center of $7 \sqrt{2} \mathrm{~mm}$ for heater size of $14 \times 14 \mathrm{~mm}^{2}$.

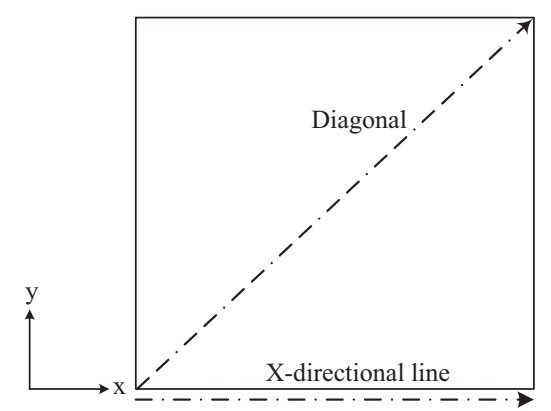

Fig. 8. Strains on the x-directional line and diagonal.

tween a pillar and the vapor core surface. Comparison with strains on the $\mathrm{x}$-directional line and diagonal are shown in Figs. 11(a)-(d). Along the $x$-directional line, the significant strain changes occur within the pillar range. For heater size of $14 \times$ $14 \mathrm{~mm}^{2}$ and $30 \times 30 \mathrm{~mm}^{2}$ with pillars, the minimum strains at the center are $1.2918 \times 10^{-4}$ and $2.1721 \times 10^{-5}$ respectively. Compare with none of pillars, the decreases in stains at the center with a pillar of $5 \sqrt{2} \mathrm{~mm}$ for heater sizes of $14 \times 14 \mathrm{~mm}^{2}$ and $30 \times 30 \mathrm{~mm}^{2}$ are about $81 \%$ and $91 \%$. Although the strain changes exist significantly with pillars along the x-direction line, the strain at the center still decrease for all types with pillars. The strain distribution situations are approximately similar.

\section{Comparison}

The average of strains in the $\mathrm{x}$-directional line and diagonal 


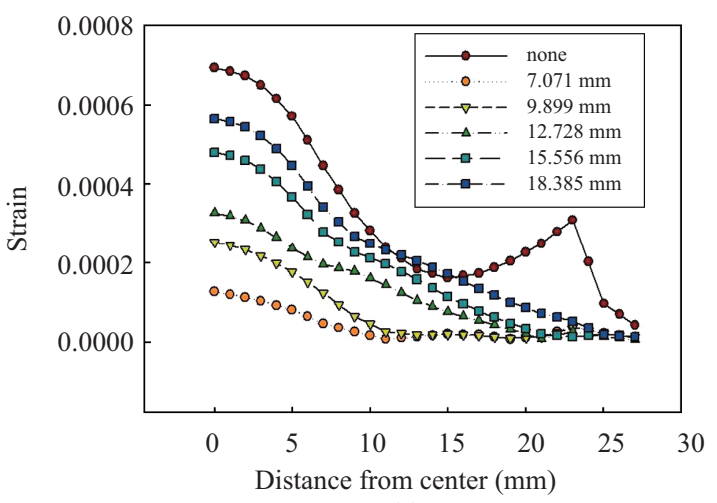

(a)

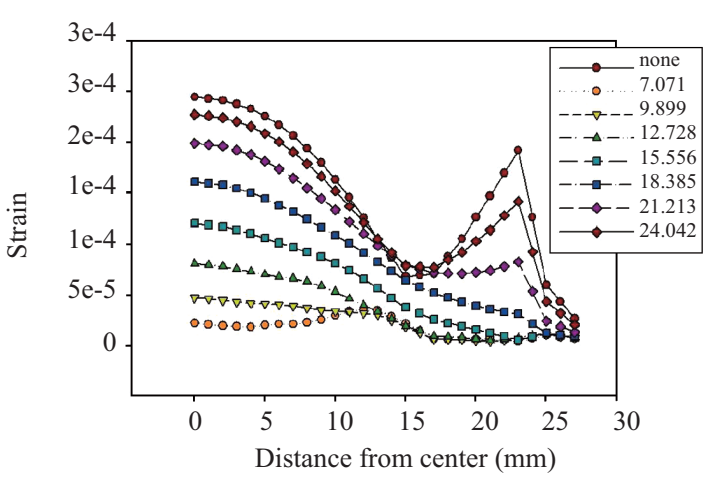

(b)

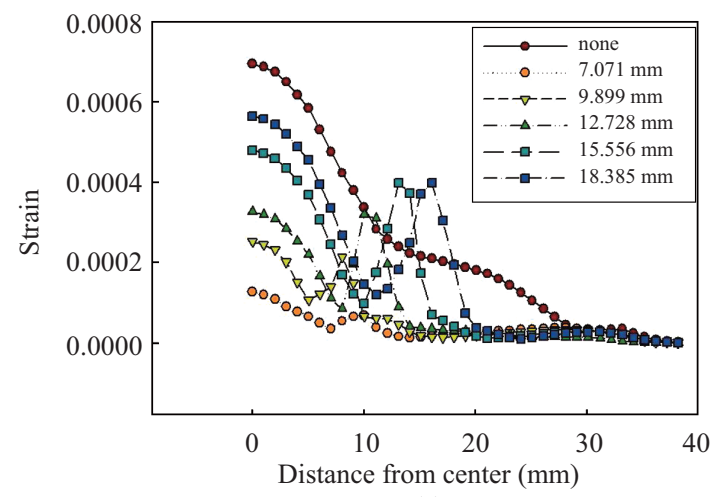

(c)

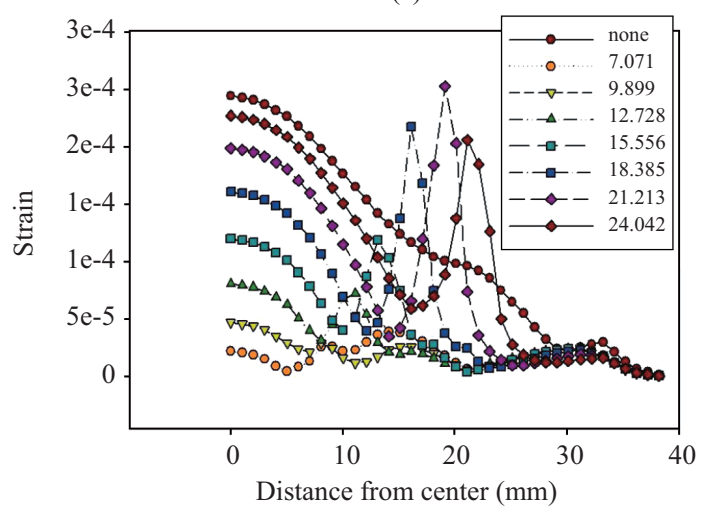

(d)

Fig. 9. (a) Strain distribution of Type I along x-directional line for heater size $14 \times 14 \mathrm{~mm}^{2}$, (b) Strain distribution of Type I along $\mathrm{x}$-direction for heater size $30 \times 30 \mathrm{~mm}^{2}$, (c) Strain distribution of Type I along a diagonal for heater size $14 \times 14 \mathrm{~mm}^{2}$, (d) Strain distribution of Type I along a diagonal for heater size $30 \times 30 \mathrm{~mm}^{2}$.

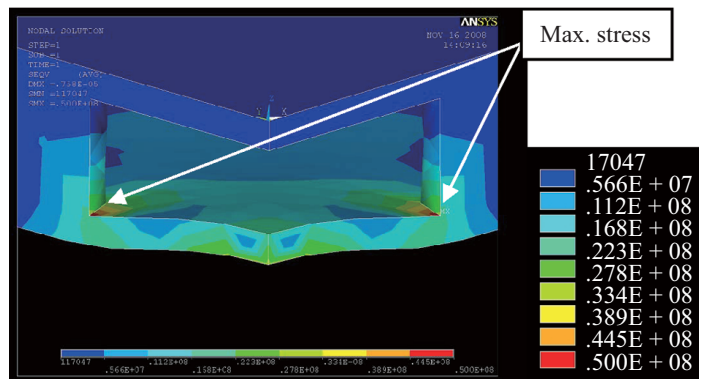

Fig. 10. The stress distribution with pillars of Type II distance from the center of $7 \sqrt{2} \mathrm{~mm}$ for heater size of $14 \times 14 \mathrm{~mm}^{2}$.

within a heater area and a vapor core area are shown in Figs. 12(a)-(d). The vapor chambers with pillars of distance from $5 \sqrt{2} \mathrm{~mm}$ obtain minimum average strains whether for the heater size or distance from center of pillars. The abovementioned results indicate that the pillars in the heater area near the center can decrease strains efficiently. Nevertheless, the heater area is relative reduced due to setting pillars. It is important to maintain heater area for effect on the working process of a vapor chamber. Considering that a pillar occupies heater size and the decrease in strain is listed in Table 2. The percentage of pillar occupation is represented ratio of pillar area and heater area within the heater. For heater size of $14 \times$ $14 \mathrm{~mm}^{2}$, the percentage of pillar occupation in the heater area reduces from $25.7 \%$ to $6.4 \%$ and the strain reduces from $85.4 \%$ to $69.9 \%$. However, the percentage of pillar occupation within the heater area of $30 \times 30 \mathrm{~mm}^{2}$ reduces from $5.6 \%$ to $1.4 \%$ and the strain substantially reduces from $86.7 \%$ to $19.9 \%$. Above-mentioned, it is obvious that the big heater size has major influence on strain decrease.

In addition, according to comparing positions along line of Type I and Type II, strains by positions along line of Type I are slightly better than others. The thicknesses of top and bottom wall are $1 \mathrm{~mm}$ respectively. Figure 13 shows the effect of thickness on the strain differences in the heater area. The observations present that increasing thickness by $40 \%$ leads to $39.2 \%$ reduction in the strain. On the other hand, decreasing thickness by $40 \%$ leads to $131.6 \%$ increment in the strain. Hence, decreasing thickness is found to have significant influence on the strain.

Aluminum is substituted for copper and the physical properties shown in Table 3. The vapor core strain of aluminum vapor chamber without pillars is greater than copper and rises to about four and six times for heater size of $14 \times 14 \mathrm{~mm}^{2}$ and $30 \times 30 \mathrm{~mm}^{2}$ respectively. Furthermore, decreases in strains of aluminum vapor chamber with pillars of $5 \sqrt{2} \mathrm{~mm}$ are $60.3 \%$ and $57.8 \%$ less than ones of copper are $86.1 \%$ and $86.5 \%$ for heater size of $14 \times 14 \mathrm{~mm}^{2}$ and $30 \times 30 \mathrm{~mm}^{2}$ respectively. In other words, decreasing strains with pillars for copper is more effective than aluminum. 


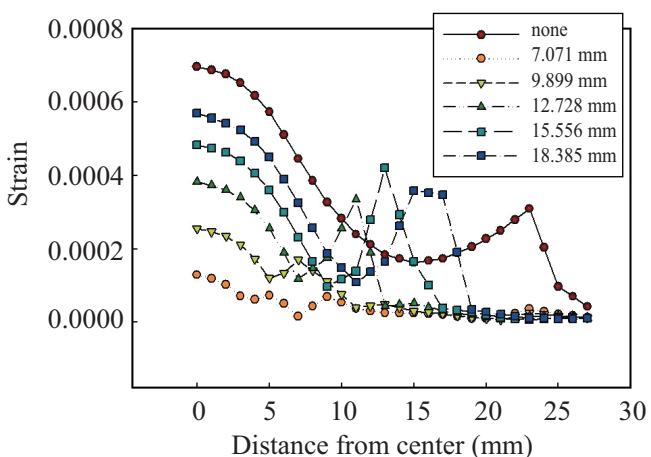

(a)

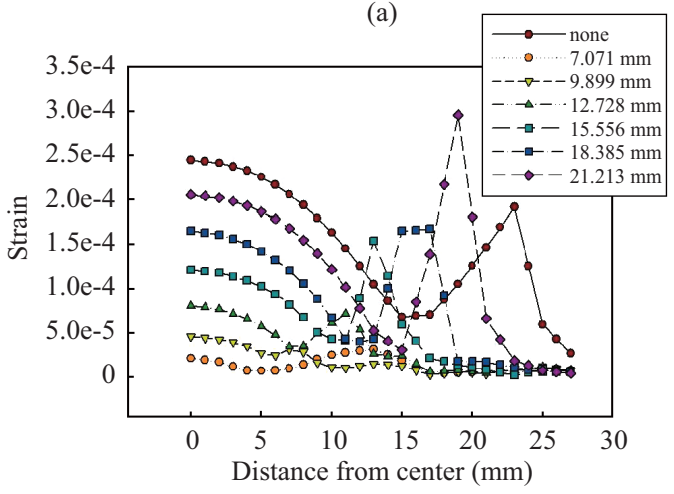

(b)

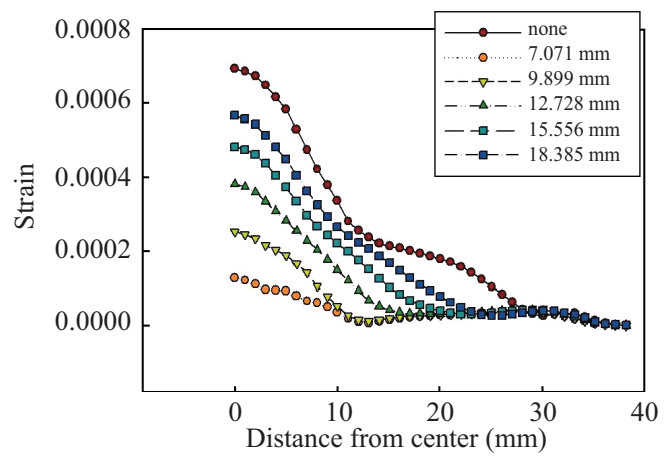

(c)

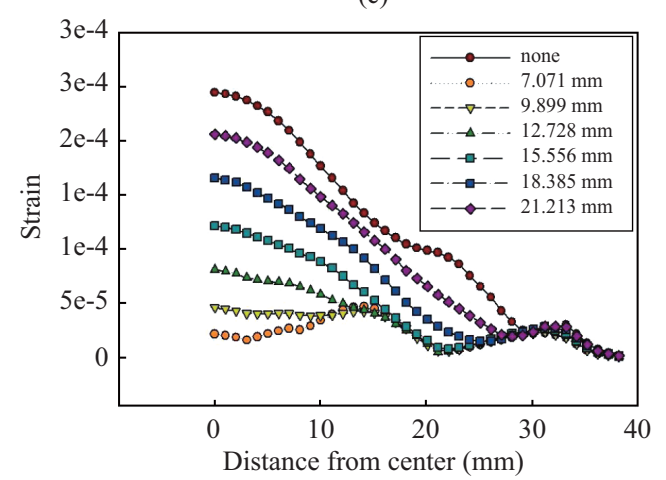

(d)

Fig. 11. (a) Strain distribution of Type II along $x$-directional line for heater size $14 \times 14 \mathrm{~mm}^{2}$, (b) Strain distribution of Type II along x-directional line for heater size $30 \times 30 \mathrm{~mm}^{2}$, (c) Strain distribution of Type II along a diagonal for heater size $14 \times 14 \mathrm{~mm}^{2}$, (d) Strain distribution of Type II along a diagonal for heater size $30 \times 30 \mathrm{~mm}^{2}$.

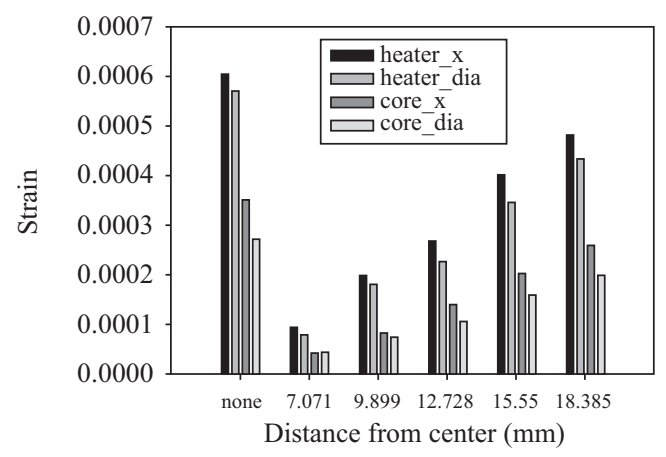

(a)

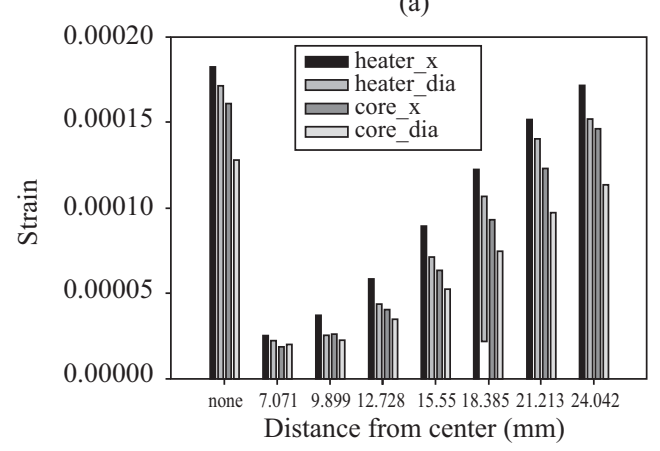

(b)

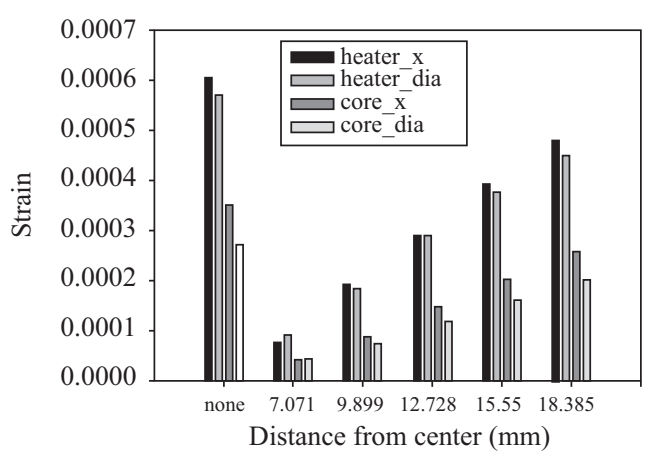

(c)

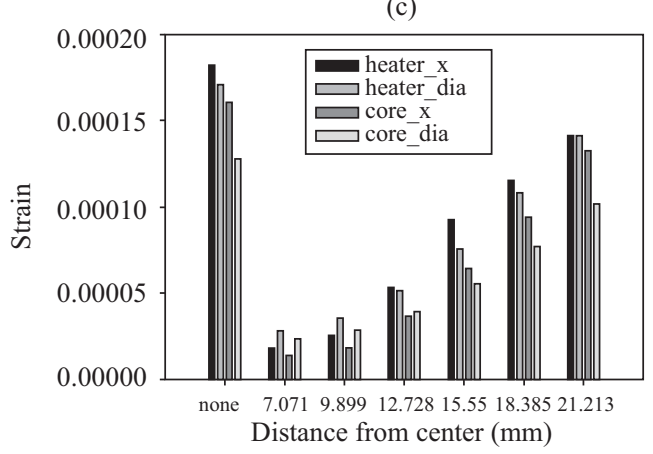

(d)

Fig. 12. (a) The average of strains along the $x$-directional line and diagonal within the heater area of $14 \times 14 \mathrm{~mm}^{2}$ and vapor core for Type $I$, (b) The average of strains along the $x$-directional line and diagonal within the heater area of $30 \times 30 \mathrm{~mm}^{2}$ and vapor core for Type $I$, (c) The average of strains along the $x$-directional line and diagonal within the heater area of $14 \times 14 \mathrm{~mm}^{2}$ and vapor core for Type II, (d) The average of strains along the $x$-directional line and diagonal within the heater area of $30 \times 30 \mathrm{~mm}^{2}$ and vapor core for Type II. 
Table 2. The percentage of pillar occupation and strain decrease within the heater area.

\begin{tabular}{|l|c|c|}
\hline \multicolumn{1}{|c|}{ Heater area } & $14 \times 14$ & $30 \times 30$ \\
\hline Pillar occupation for location 7.071 & $25.7 \%$ & $5.6 \%$ \\
\hline Strain decrease on vapor core area & $85.6 \%$ & $86.6 \%$ \\
\hline Pillar occupation for location 9.899 & $6.4 \%$ & \\
\hline Strain decrease on vapor core area & $70.1 \%$ & \\
\hline Pillar occupation for location 21.213 & & $1.4 \%$ \\
\hline Strain decrease on vapor core area & & $20.2 \%$ \\
\hline
\end{tabular}

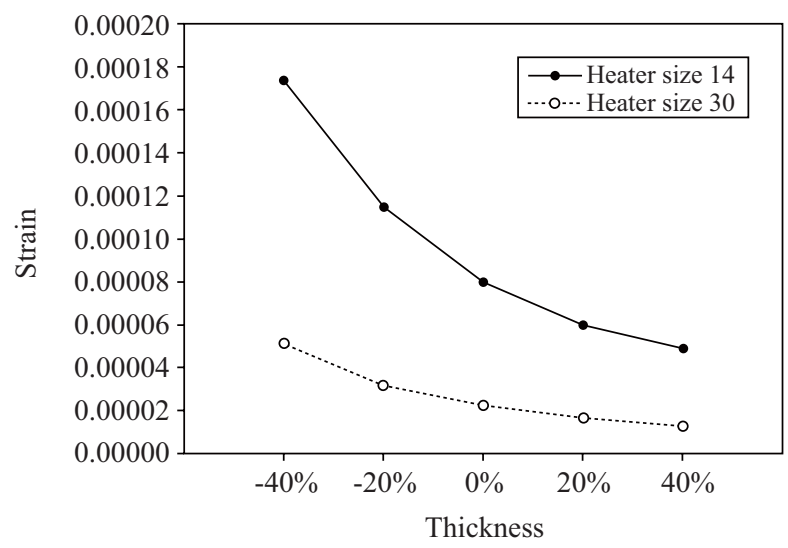

Fig. 13. Effect of wall thickness on strain of vapor chamber.

Table 3. The physical property.

\begin{tabular}{|c|c|}
\hline Property & Aluminum \\
\hline Young's modulus & $7.0 \times 10^{10} \mathrm{~N} / \mathrm{m}^{2}$ \\
\hline Poisson's ratio & 0.35 \\
\hline Density & $2700 \mathrm{~kg} / \mathrm{m}^{3}$ \\
\hline Thermal conductivity & $237 \mathrm{w} / \mathrm{m}^{\circ} \mathrm{C}$ \\
\hline Coefficient of thermal expansion & $2.4 \times 10^{-5} \mathrm{~m} /{ }^{\circ} \mathrm{C}$ \\
\hline
\end{tabular}

\section{CONCLUSIONS}

This paper studies a stress-strain analysis of a vapor chamber with pillars by finite element method. The strains in the bottom surface are investigated parameters of pillar positions distance from the center, locations of Type I and Type II, heater sizes, and materials. Conclusions are listed as follows:

(1) The maximum stress is occurred at the bottom of the pillars. The stress centralization is due to pillars hold a vapor chamber.

(2) When the percentage of pillar occupation within the heater area of $14 \times 14 \mathrm{~mm}^{2}$ is changed from $25.7 \%$ to $6.4 \%$, the strain of the vapor chamber can be reduced from $85.4 \%$ to $69.9 \%$. When the percentage of pillar occupation within the heater area of $30 \times 30 \mathrm{~mm}^{2}$ is changed from
$5.6 \%$ to $1.4 \%$ and the strain can be substantially reduced from $86.7 \%$ to $19.9 \%$. In other words, the larger heater has a major influence on strain decrease.

(3) Increasing thicknesses of top and bottom surface by $40 \%$ leads to a $39.2 \%$ reduction in the strain. However, decreasing by $40 \%$ leads to a $131.6 \%$ increment. Hence, decreasing thickness is found to have significant influence on the strain.

(4) The aluminum vapor chamber is compared with copper one. It is expected that strains of aluminum are greater than ones of copper. Strain decreases for aluminum vapor chamber with pillars of $5 \sqrt{2}(7.071) \mathrm{mm}$ are less than ones of copper.

\section{REFERENCES}

1. Chanchani, R. and Hall, P. M., "Temperature dependence of thermal expansion of ceramics and metals for electronic packages," IEEE Transactions on Components, Hybrids, and Manufacturing Technology, Vol. 13, No. 4, pp. 743-750 (1990).

2. Chiang, T. Y., Souri, S. J., Chui, C. O., and Saraswat, K. C., "Thermal analysis of heterogeneous 3-D ICs with various integration scenarios," Technical Digest-International Electron Devices Meeting, pp. 581-684 (2001).

3. Chong, D. Y. R., Kapoor, R., and Sun, A. Y. S., "Reliability assessment of a high performance flip-chip BGA package (organic substrate based) using finite element analysis," Electronic Components and Technology Conference, pp. 1425-1430 (2003).

4. Chuang, C. C., Yang, T. F., Juang, J. Y., Hung, Y. P., Zhan, C. J., Lin, Y. M., Lin, C. T., Chang, P. C., and Chang, T. C., "Influence of underfill materials on the reliability of coreless flip chip package," Microelectronics Reliability, Vol. 48, No. 11-12, pp. 1875-1881 (2008).

5. Do, K. H., Kim, S. J., and Garimella, S. V., "A mathematical model for analyzing the thermal characteristics of a flat micro heat pipe with a grooved wick," International Journal of Heat and Mass Transfer, Vol. 51, No. 19-20, pp. 4637-4650 (2008).

6. Huja, M. and Husak, M., "Thermal microactuators for optical purpose," Proceeding International Conference on Information Technology: Coding and Computing, pp. 137-142 (2001).

7. Kim, S. H., Park, H., and Suzuki, K., "Thermo-mechanical reliability of high-end flip chip BGA packages: comparison heat spreader and motherboard construction," Proceeding-Electronic Components and Technology Conference, Vol. 1, pp. 38-43 (2005).

8. Lee, Y. C., Wang, B. T., Lai, Y. S., Yeh, C. L., and Chen, R. S., "Finite element model verification for package printed circuit board by experimental modal analysis," Microelectronics Reliability, Vol. 48, No. 11-12, pp. 1837-1846 (2008).

9. Qi, Q., "Meeting thermal performance and reliability challenges for a thermally enhanced ball grid array package (TEBGA)," International Conference on Electronic Package Technology \& High Density Packaging (ICEPT-HDP 2008), pp. 1-6 (2008).

10. Rodriguez, M. P. and Shammas, N. Y. A., "Finite element simulation of thermal fatigue in multilayer structures: thermal and mechanical approach," Microelectronics and Reliability, Vol. 41, No. 4, pp. 517-523 (2001).

11. Vadakkan, U., Chrysler, G. M., and Sane, S., "Silicon/water vapor chamber as heat spreaders for microelectronic packages," 21st IEEE Semi-Therm Symposium, pp. 182-186 (2005).

12. Zhang, X., Wong, E. H., Lee, C., Chai, T. C., Ma, Y., Teo, P. S., Pinjala, D., and Sampath, S., "Thermo-mechanical finite element analysis in a multichip build up substrate based package design," Microelectronics Reliability, Vol. 44, No. 4, pp. 611-619 (2004). 